\title{
Dual roles and dual identities: enhancing the experience of in-service teacher training in English Further Education
}

\author{
Kevin Orr \\ University of Huddersfield \\ HUDCETT
}

\begin{abstract}
In marked distinction from other sectors of education, around 90 percent of Further Education (FE) staff in England are employed untrained and complete their Initial Teacher Training (ITT) on a part-time in-service basis. By consequence, these staff sustain the dual role of employed teacher and teacher-trainee usually at the beginning of their career. This paper reports on a project funded by ESCalate which researched the dual roles and dual identities of employee and trainee on in-service FE teacher-training courses. It argues that the lack of a culture of pedagogical development in colleges along with the pressure for trainees to quickly cope with teaching can lead to conservative practice as expedience may be prioritised over flair. In response, the paper makes recommendations to enhance the experience and development of in-service teacher trainees.
\end{abstract}

\section{Key words}

Further Education; Initial Teacher Training; Pedagogy; Identity; Policy.

\section{Introduction}

After many decades of neglect the FE sector in England has found itself since 1997 at the centre of the government policy and there has been a consequent effort to regulate and professionalise FE teaching through a raft of initiatives and reforms. These include the statutory requirement for teachers in FE colleges to become teacher-qualified, but in stark contrast to the situation in English schools 90 percent of FE teachers are employed without a teaching qualification and complete their teacher training on a part-time in-service basis (Ofsted, 2003). Therefore, these trainees have the dual role and dual identity of employee and learner, which affects their development as teachers as well as the wider development of pedagogy in FE. This article is based on a research project funded by ESCalate which explored the experience of trainees, teacher educators and Human Resources (HR) managers in relation to in-service teacher training at two FE colleges.

\section{The history of ITT in English FE}

Whilst teachers in colleges have usually held qualifications in their own vocational area or subject, until a decade ago it was not unusual for them to be employed and remain in post without ever gaining teaching qualifications. This reflected an emphasis on craft or subject over pedagogical proficiency that derived from the predominantly vocational nature of Further Education (Simmons, 2008: p. 367). Many FE colleges originated in the mechanics institutes and technical colleges of the late-nineteenth and early-twentieth centuries where a skilled and experienced artisan or practitioner was expected to pass on what they knew. An implicit assumption was that subject expertise, not skill as an educator was the main determinant of the quality of teaching and learning. Moreover, the need to employ teachers with current expertise in specialist areas further sustained this situation and, just as now, these people had to keep earning while training as a teacher. However, the consequence of this was that many FE teachers regarded themselves chiefly as engineers, hairdressers or joiners who gained professional credibility through their craft knowledge, not through their teaching skills (Robson et al, 2004). The Institute for Learning (IfL Vision and Strategy web page, 2009) refers in positive terms to the dual professionalism of FE staff; that is, professionalism related to craft or subject allied with professionalism related to teaching. However, the continuing identity with their former profession may be at the expense of pedagogy and may prevent some FE staff from even considering themselves as professional teachers. Formal teacher training courses have existed since the Second World War (Bailey, 2007: p. 280), but until 2001 there was no obligation for teachers to be qualified and ITT in FE remained 'voluntarist, haphazard and uneven' (Lucas, 2007: p. 18). By consequence and despite recent initiatives, FE has not had a culture of professional development related to pedagogical practice and there is no tradition of nurturing new staff as in the schools sector.

The election of the New Labour government in 1997 marked a transformation of FE's fortunes because the government identified the sector's role in enhancing social justice through widening participation in education and training and in enhancing the country's competitiveness through a highly-skilled workforce (see for example DfES, 2002 and DfES, 2006 ). This conjoining of skills, competitiveness and social justice is disputed (see inter alia Coffield, 1999 and Avis, 2007), but the sector's importance to the government in recent years has seen the sector receive significantly increased levels of funding as well as much closer scrutiny. Keep (2006) argues that FE in England is now the most highly regulated and centrally directed education system in Europe, which also applies to ITT in FE. One significant aspect of this regulation is the statutory standards relating to teachers in FE colleges, most recently the New Overarching Professional Standards For Teachers, Tutors And Trainers In The Lifelong Learning Sector produced by Lifelong Learning UK (LLUK) which took effect in 2007. The hundreds of separate descriptors of knowledge and ability contained within these standards contrast to the single page of broad statements that cover staff in HE or the much simpler statement of values for school teachers (Orr, 2008: p. 103). The extent of these standards and their detailed direction of practice may be a response to the lack of a tradition of pedagogical development in $\mathrm{FE}$, but inherent within these standards is the idea that teaching and teacher training in FE can be measured and regulated. 
Various government-funded bodies and agencies nationally prescribe much of the content of FE teacher training courses which are subject to 'annual monitoring' against national standards if official 'endorsement' is to be maintained (Simmons and Thompson, 2007: pp. 176-177). This view of teaching as a primarily technical activity to be measured and regulated affects not just the structure and content of IT'T courses, but the perception of teaching that many trainees hold.

\section{The research project}

Like Lucas and Unwin (2009) and Viskovic and Robson (2001) amongst others who have written about ITT in FE, this project sought to place the in-service training of FE teachers within the extensive field of research into Work Based Learning (WBL). This has focused on what is learnt through enculturation in a workplace (see for example Rainbird et al, 2004) and considers learning as contingent upon the relationship between the individual and their circumstances. Inherent in researching WBL is the problem that all learning is often conceived in terms of formal education (Eraut, 2004: p. 249; Boud and Solomon, 2003: p. 328) and the conventional cultural discourse of learning is school-oriented. This can mean that people do not notice or perceive what they have learnt or 'picked up' at work because it is considered as normal practice. In research interviews the important and complex mundane may be ignored while insignificant but easily-explained discrete items of formal learning may be highlighted. This problem is heightened when the trainee workers are also attending a course, as in the case of teacher trainees in FE colleges. Therefore, for this project the development of these trainees was primarily conceptualised as changing identity rather than increasing knowledge or skills. Learning 'implies becoming a different person...To ignore this aspect of learning is to overlook the fact that learning involves the construction of identities' (Lave and Wenger, 1991: p. 53). Lave and Wenger's notion of 'becoming' enabled an understanding of identity as being formed or improvised within a social space, which can both enable and restrict individual agency. This informed our understanding of the development of the in-service trainees that participated in our research, each of whom had two distinct identities and roles, as trainee and teacher.

The empirical research took place between December 2008 and May 2009 at two FE colleges in the north of England - 'Dale College' and 'Urban College'. Despite their differences, both institutions mainly provide vocational education and training for their local communities. Dale College has undergone significant growth over recent years, but it is still a relatively small and stable institution. The main site is located in a market town and serves a predominantly rural area. In contrast, Urban College is a much bigger institution located in a large conurbation. Both institutions are part of a large network of institutions that offer the Certificate of Education (Cert Ed) as well as the Professional Graduate Certificate in Education (PGCE) for trainee teachers with degrees. These courses are designed and validated by 'Northern University', which has a long-standing reputation for providing teacher education in the sector. Whilst the University writes the curriculum, each college's own teacher educators actually deliver the course. The Cert Ed and PGCE trainees together normally attend a three-hour class once a week for two years during which time they are also employed, full-time or part-time, as teachers in various institutions, the majority at the college where they are also studying.

Face-to-face semi-structured interviews were conducted with two teacher educators and an HR manager at each college and by telephone with a total of 20 trainee teachers from the two colleges. These trainees were teaching on a wide range of courses including social care, agriculture, leisure and tourism, business studies, art, drama, hairdressing and public services. Most had joined the course on being employed and consequently had been teaching for only a short time, though some had had longer experience either in FE or elsewhere. The four teacher educators had been involved in teacher education for between five and 24 years and had extensive previous experience of FE. The managers were in charge of HR at their college and had responsibility to ensure staff held appropriate qualifications. In neither case did they directly line manage the teacher education team. Though the sample is small, this research has allowed an insight into the experience of the in-service teacher training experience to reveal some of the issues for those involved.

\section{Findings}

"I don't think, for the most part, I'm conceived as a trainee teacher in terms of responsibilities that I've been given..."

This comment from a second-year trainee at Urban College expresses the central contradiction of the in-service trainee. She was new to teaching, which she was enjoying, and by her own account she was managing the challenges of running a Uniformed Public Services course well. However, despite being a trainee, the college had the same expectations of her as a fully qualified teacher. That central contradiction was widely evident, but though this research was limited to two colleges, the diversity of experience of the trainees even within those institutions was striking. The support each was offered, their caseload and their capacity to cope were dependent upon often highly localised factors interacting with their own lived biography and wherewithal (Dixon et al, 2008). Nonetheless, both the general attitude to trainee teachers, however benevolent, and how they described themselves, suggested that coping was what counted above all else. This attitude was also expressed by the HR managers and to a lesser extent by some of the teacher educators, albeit sympathetically. Unfortunately, coping can imply a very restricted notion of teaching that allows little space for experimentation or innovation of practice.

Dale College gave no remission of teaching for employees who were on ITT courses. Employees at Urban College officially received 50 hours remission, though none of the trainees interviewed had received as much as this. Their ITT tutors described the importance of their own position to enhance the quality of teaching across the college and the trainees at both colleges frequently contrasted the usefulness of the teaching observations carried out by the ITT tutor compared to those carried out for quality assurance in the college. ITT tutors gave more specific and developmental feedback: 
'I mean we've got the ones from college which are the quality control type observations and somebody just pops in and they're all right; and the ones from the teacher trainers are great because you get loads of feedback and that is really what you need."

More generally, the trainees were positive about the Cert Ed/PGCE course, though some were unequivocal about the separation between the ideal of good practice promoted on the course and the harsher reality of real day-to-day teaching. As one second year trainee at Dale College put it:

"... on the PGCE course we're kind of being taught best practice and it's quite easy to be sometimes in the work mode where best practice can get overlooked so there is a bit of a tension for me there as someone who has only been teaching for a year."

This discrepancy between the ITT course and the day-to-day practice of trainees was also noted by the teacher educators. Nevertheless, trainees enjoyed mixing with colleagues from other disciplines and departments and the weekly ITT classes were often the only place where they were considered trainees by others or even themselves. To admit to being a trainee elsewhere was to admit weakness. Along with the lack of remission of teaching while training, this is symptomatic of the absence of a tradition or culture of developing new entrants to the profession, which is further reflected by the HR manager at Urban College who stressed the limited role of teacher educators:

'Their role is primarily as any other lecturer; it's just that they teach a different subject... so they will get people asking them more questions, if you like but, to all intent and purposes, they will be the same as any other lecturer."

Though this view was not supported at Dale College there was little distinction in the treatment of teacher educators between the two institutions. Nonetheless, trainees appreciated the Cert Ed/PGCE tutors for their structured lessons, their guidance and support. The tutors themselves emphasised the supportive, caring aspect of their practice and yet there was evidence that that support could be uncritical and trainees were occasionally praised for merely coping, thus allowing dull or conservative practice to flourish unchallenged.

There was little antipathy to the theoretical element of the course, but for many trainees this was quite separate and less useful than what one trainee referred to as "on the job, practical, hands-on stuff that I could use day-to-day in the classroom". This again suggests the separation of the course from teaching practice, but it also suggests a restricted notion of professional knowledge. Moreover, theory was identified by other trainees as items of propositional knowledge such as "experiential learning cycles", "the different theories" or most commonly and uncritically, learning styles. Theorisation was not considered as a means to analyse or extend practice and some trainees had simply accepted the theory that had validated or given a name to their existing practice. One first year student said:

'We've looked at learning models and learning styles so far and a lot of the things that are there I've already been doing; I just didn't know I was doing them."

Many more commented upon the prescriptive and bureaucratic nature of the course, usually expressed in the term "paperwork," which referred to the forms relating to, for example, written reflections, teaching observations and meetings with mentors.

"I didn't realise [it] would be so prescriptive. I thought there would be a lot more freedom. So that was different to what I expected. It was very, very precise and you had to deliver to the exact prescribed criteria."

This foregrounding of the course's performative elements, which are largely in place to meet the strictures of governmentfunded agencies, melds with the form-filling performative elements of the teacher's role as this interview extract illustrates:

'I think it's just the paperwork that goes with it which is the biggest issue that I've got. There's too much paperwork which I really don't know that much about and people are ringing me up and saying: 'where's that form?' and I don't even know what that form is."

Thus, the course and teaching were perceived at least partly in terms of their administration, which they had little control over; for example the scheme of work as an artefact was emphasised over the process of lesson planning, writing up reflections was highlighted rather than actually thinking about lessons. In this way a limited understanding of teaching practice is constructed for the in-service trainee, as the dual identities of trainee and teacher meet and integrate over a need to manage and perform both in the classroom, and on the ITT course. The trainee's right to experiment and make mistakes is eclipsed and the teacher is quickly identified as someone who can handle the workload, not someone who actively develops their practice.

\section{Recommendations}

Though the absence of a culture of development in FE requires attention, recommendations to organisations about ITT in FE must be made cautiously. There is much over which employers and teacher educators have little influence, not least the pertaining regulatory regime, and the sector's diversity requires intervention that is sensitive to local influences. Moreover, any changes risk adding to the already full workload of FE staff, which may only further reinforce expedience or performativity. With those caveats in mind, these recommendations are primarily about allowing trainee teachers to develop their practice, not just to learn to cope.

- Recognise trainees as a defined category of employee.

Just as schools have procedures for newly-qualified teachers, so should FE organisations, especially in relation to teaching observations. New teachers should be encouraged to see themselves as trainees and so have the licence to 
experiment and to learn from mistakes. This would also mean that induction would involve pedagogical development and would involve the teacher education section and the trainee's manager as well as the HR department.

- Increase trainees' workload incrementally.

As is the practice in schools, trainees should initially have reduced workloads to allow them to observe colleagues, to plan lessons carefully, and to think about how they might develop their practice informed by discussion and their own experience. This may help to prioritise the development of pedagogy through experimentation over expediency. Fulltime and fractional teachers should be timetabled to teach for approximately two-thirds of their scheduled class contact time during the first term of their ITT course and for three-quarters of their scheduled class contact time for the remainder of their time on the course.

- Formally recognise the key role of teacher educators.

Teacher educators can play a crucial role in developing and supporting trainee teachers and enhancing the standard of teaching in the college. However, teacher educators need to have the necessary time to challenge and stretch trainees as well as support them, which requires a reduced teaching timetable.

- Enhance the status of mentors.

Despite their importance, the procedure to become a mentor and what the role involves are uneven and apparently random. Ideally, mentors should be volunteers; they should have the opportunity to train; and each mentor should have one hour per week remission for each trainee to enable them to spend time with the new teacher.

- Prioritise the teacher training course.

Trainees were sometimes instructed by line managers not to attend Cert Ed/PGCE classes so as to cover for absent staff, which reinforces a perception of teacher training as extra, not integral. Senior managers should explicitly and consistently prioritise the ITT course and ensure that trainees and their line managers are aware of its importance for both the individual teacher's and the organisation's development.

- Alleviate the bureaucratic elements of the course.

Although teacher educators have limited control over many elements of ITT courses, they can actively prioritise pedagogy over the completion of forms. Expediency should not be at the expense of meaningfully expanding teaching knowledge and practice. Issues of teaching and learning need to be at the centre of trainees' experience, not concerns about filling out the right box.

- Increase integration and relevance of theory.

Teacher educators should consider what professional knowledge a new teacher in the sector requires. This would include both what theory is covered on ITT courses and how it is presented to enhance the relevance of theory to trainees, which may well entail a move towards, for example, theories of situational and social learning. Above all, trainees should be able to analyse and critique theorisation as well as being able to use it to analyse and critique their own work.

- Consider how trainees can be supported to maintain challenge.

Sympathetically supporting trainees who are struggling with the pressures of teaching is important and valuable. However, it can lead teacher educators to unduly praise trainees' existing practice and so to validate and perpetuate dreary, unadventurous pedagogy. Therefore, teacher educators should consider how they support and challenge trainees and encourage them to try new and alternative forms of practice.

\section{Conclusion}

The heavy workload of new teachers greatly restricts opportunities for innovation or experimentation due to the need to quickly cope, which favours conservative teaching practice. These recommendations are intended to recognise that situation though it is one that only the government can adequately alleviate. However, this tendency to conservative practice may be exacerbated by teacher educators' sensitivity to the new teachers' anxiety and their wish to support these new teachers. More generally, FE has not historically promoted development as an integral part of being a teacher, in contrast to law or health professionals. Vocational expertise was perceived as necessary but pedagogic expertise was perceived as optional. Recent efforts to professionalise the FE workforce through initiatives such as national standards for teachers and the requirement to hold teaching qualifications may be a response to this situation. Yet, these initiatives have added to the demands on trainee teachers and reinforced a perception of teaching as, in part, a bureaucratic exercise. This correlates with the perception that learning to teach in FE is about learning to cope in difficult circumstances. However, while expediency has precedence over flair, the pedagogy and profession of FE teachers cannot develop.

\section{References}

Avis, J. (2007) Education Policy and Social Justice. London: Continuum.

Bailey, B. (2007) 'The Establishment Of Centres For The Training Of Teachers In Technical And Further Education In England, 1933-1950', Journal of Vocational Education and Training Vol. 59, No. 3, pp. 279-294. http://dx.doi.org/10.1080/13636820701520260

Boud, D., Solomon, N. (2003) “'I Don’t Think I Am A Learner”: Acts Of Naming Learners At Work', Journal of Workplace Learning Vol. 15, No. 7/8, pp. 326331. http://dx.doi.org/10.1108/13665620310504800

Coffield, F. (1999) 'Breaking the Consensus: Lifelong Learning As Social Control', British Educational Research Journal Vol. 25, No. 4, pp. 479-499. http://dx.doi.org/10.1080/0141192990250405

Department for Education and Skills (DfES) (2002) Success for All: Reforming Further Education and Training. London: Stationery Office.

Department for Education and Skills (DfES) (2006) Further Education: Revising Skills, Improving Life Chances. London: HMSO. 
Dixon, L., Jennings, A., Orr, K., Tummons J. (2008) 'Dominant Discourses Of Pre-Service Teacher Education And The Exigencies Of The Workplace: An Ethnographic Study From English Further Education'. Paper presented at BERA Conference 3-5 September 2008. Heriot-Watt University, Edinburgh.

Eraut, M. (2004) 'Informal Learning In The Workplace', Studies in Continuing Education Vol. 26, No. 2, pp. 247-273. http://dx.doi.org/10.1080/158037042000225245

Institute for Learning (IfL) (2009) website available online at www.ifl.ac.uk [last accessed 26 July 2009].

Keep, E. (2006) 'State Control Of The English Education And Training System - Playing With The Biggest Train Set In The World', Journal of Vocational Education and Training Vol. 58, No. 1, pp. 47-64. http://dx.doi.org/10.1080/13636820500505819

Lave, J., Wenger, E. (1991) Situated Learning. Cambridge: Cambridge University Press.

LLUK (2007) New Overarcbing Professional Standards For Teachers, Tutors And Trainers In The Lifelong Learning Sector. London: LLUK.

Lucas, N. (2007) 'Rethinking Initial Teacher Education For Further Education Teachers: From A Standards-Led Approach To A Knowledge-Based Approach', Teaching Education Vol. 12, No. 1, pp. 1-17. http://dx.doi.org/10.1080/10476210701325077

Lucas, N., Unwin, L. (2009) 'Developing Teacher Expertise At Work: In-Service Trainee Teachers In Colleges Of Further Education In England (Paper)', Institute of Education, University of London.

Ofsted (2003) The Initial Training of Further Education Teachers: A Survey. HMI 1762. London: Ofsted.

Orr, K. (2008) 'Room For Improvement? The Impact Of Compulsory Professional Development For Teachers In England's Further Education Sector', Journal of In-Service Education Vol. 34, No. 1, pp. 97-108. http://dx.doi.org/10.1080/13674580701832627

Rainbird, H., Fuller, A., Munro, A. (Eds) (2004) Workplace Learning in Context. London: Routledge.

Robson, J., Bailey, B., Larkin, S. (2004) 'Adding Value: Investigating The Discourse Of Professionalism Adopted By Vocational Teachers In Further Education Colleges', Journal of Education and Work Vol. 17, No. 2, pp. 183-195. http://dx.doi.org/10.1080/13639080410001677392

Simmons, R. (2008) 'Golden Years? Further Education Colleges Under Local Authority Control', Journal of Further and Higher Education Vol. 32, No. 4, pp. 359-371. http://dx.doi.org/10.1080/03098770802395579

Simmons, R., Thompson, R. (2007) 'Aiming Higher: How Will Universities Respond To Changes In Initial Teacher Training For The Post-Compulsory Sector In England?', Journal of Further and Higher Education Vol. 1, No. 2, pp. 171-182. http://dx.doi.org/10.1080/03098770701267663

Viskovic, A., Robson, J. (2001) 'Community And Identity: Experiences And Dilemmas Of Vocational Teachers In Post-School Contexts', Journal of In-Service Education Vol. 27, No. 2, pp. 221-236. http://dx.doi.org/10.1080/13674580100200156 